\title{
Effect of growth media and foliar application of macro nutrients on agronomic performance of strawberry
}

\author{
Umbreen Shahzad $^{1 *}$, Sundas Rasheed ${ }^{1}$, Tauqeer Ahmad Yasir ${ }^{1}$, \\ Muhammad Shah Jahan ${ }^{2}$, Zeshan Hassan ${ }^{1}$, Allah Wasaya ${ }^{1}$ and Abdul \\ Wahid Baloch ${ }^{3}$ \\ 1. College of Agriculture, Bahauddin Zakariya University, Bahadur Sub-Campus Layyah, Pakistan \\ 2. Department of Plant Pathology, PMAS-Arid Agriculture University Rawalpindi, Pakistan \\ 3. Department of Plant Breeding \& Genetics, Sindh Agriculture University, Tandojam-Pakistan \\ *Corresponding author's email: umbreenshahzad@bzu.edu.pk
}

Citation

Umbreen Shahzad, Sundas Rasheed, Tauqeer Ahmad Yasir, Muhammad Shahjahan, Zeshan Hassan, Allah Wasaya and Abdul Wahid Baloch. Effect of growth media and foliar application of macro nutrients on agronomic performance of strawberry. Pure and Applied Biology. Vol. 6, Issue 4, pp1457-1463.

http://dx.doi.org/10.19045/bspab.2017.600157

Received: 04/09/2017

Revised: 07/11/2017

Accepted: 17/11/2017

Online First: 30/11/2017

\section{Abstract}

Strawberry (Fragaria ananasa), belongs to rosaceae family, which is rich in vitamins and minerals. The requirement of optimized media is very important because plant growth is largely dependent upon the physiochemical properties of the growing media usded for high yield and economic production of crops. Present study was conducted to evaluate the growth performance of strawberry in the different media and combination of the macro nutrients. Different media combination were used including soil, peat moss and soil+peat combination in equal proportion. Foliar application of NPK at weekly interval was done with 4ppm, 6ppm and 8ppm.The design was CRD with 3 replicates. Results revealed that strawberry plant showed better response in peat moss media with 6 and 8 ppm foliar application of NPK. Chlorophyll content at vegetative stage was maximum (19.6) at 6ppm, while at reproductive stage it was (23.69) with 4 ppm foliar application in peat moss. Maximum Number of fruits (7.21) were obtained in peat moss. Fruit weight (23.52), leaf area (625.86) and total soluble solids (7.33) were recorded maximum in peat moss with 8 and 6 ppm foliar application of NPK as compared to control. The color and the taste were also good in peatmoss media with higher doses of macro nutrients. So, plants grown in peat moss growing media showed significant increase in all parameters and gave better performance of strawberry growth and development both in vegetative as well as ass reproductive parameters.

Keywords: Strawberry; Macro nutrients; Growth media; Fragaria annanaca; Foliar spray

\section{Introduction}

Strawberry (Fragaria ananassa) belongs to Rosacea family of the genus Fragaria [1]. The strawberry plant is an herbaceous perennial. Strawberries contain a desirable amount of vitamins, fiber and sugars [2].Vitamin $\mathrm{C}$, Phenolic and flavonoids are also present in strawberry fruit [3]. Mainly 4.6-6.5 $\mathrm{pH}$ is suitable for strawberry [4]. Pakistan is producing a limited quantity of strawberries. 
The estimated per acre income of the strawberry is about Rs.100,000 per season [5].In early summer plant firstly bloom and then fruit. Vegetative growth starts in summer, after a period of rest. Peat moss is used as a soil conditioner which enhances the water holding capacity of soil. Peat moss improves the aeration condition by allowing the formation of the greater root system, promoting shoot nutrition uptake and strengthening activities of capturing light and increased yield [6]. Soilless media also give good oxygen penetration and develop good growth of the root system along with the sustainability of strawberry [7]. Along with the media, foliar application of fertilizer plays an important role in growth and yield of strawberry plant. To increase nutrient content in certain above-ground plant organism foliar nutrition is important [8] and foliar application of fertilizer usually compensates the deficiency of nutrients.

Contemporary study was designed to check the effect of growing media and foliar application of fertilizer on the strawberry plant. Cultivar "Chandler" is good candidate in future for better yield of its fruits. In Layyah region farmers are not much familiar with strawberry cultivation and limited work has been done. It is because that they do not known about its nutritional value and net price. So, the present study will guide the farmers for the optimization of production technology of strawberry in Thal region of Layyah by using different media and fertility program.

\section{Materials and methods}

The research was conducted out at Department of Horticulture BZU Bahadur
Sub-Campus Layyah in 2015-2016.The experiment was conducted out on a strawberry cv. 'Chandler' transplanted in the month of December in pots placed in the nursery area of Department of Horticulture Bahauddin Zakariya University Bahadur Campus Layyah. The soil in the experimental pots was analyzed for $\mathrm{pH}$, Electrical conductivity (EC) and for its nutrients contents. Each pot contain $1.55 \mathrm{~kg}$ of soil $\left(\mathrm{M}_{1}\right)$ while soil + peat moss contains $1.35 \mathrm{~kg}$ in each pot $\left(\mathrm{M}_{2}\right)$ and peat moss contains 0.30 $\mathrm{kg}$ in each pot $\left(\mathrm{M}_{3}\right)$. So, $\mathrm{M}_{1}$ was $100 \%$ Soil, $\mathrm{M}_{2}$ was Soil \& peat moss $(50 \%+50 \%)$ and $\mathrm{M}_{3}$ was $100 \%$ peat moss. The runners of the strawberry plants were taken from Sawat. Plants were grown in medium size pots with 3 different medias, out of 161 pots 20 pots included soil, 20 pots included soil +peat moss and only peat moss media contains 121 pots. The experiment was designed in Completely Randomized Designed (CRD) with 3 replications. $T_{1}$ treatment was applied with $4 \mathrm{ppm}$ of NPK, while $\mathrm{T}_{2}$ with $6 \mathrm{ppm}$ and $\mathrm{T}_{3}$ with $8 \mathrm{ppm}$ of NPK. Uniform weeding and cultural practices were applied for development of runners and for good growth.

\section{Data collection}

Vegetative, reproductive, qualitative and quantitative parameters were collected for comparison of plant growth under different media and fertilizer application (Table 1).

The leaf area was calculated by measuring length and width of leaves in millimeters $(\mathrm{mm})$. The length and width of leaves of each plant was taken by using "Digital Vernier caliper $(0-150 \mathrm{~mm})$.

Leaf Area $=$ Length $(\mathrm{mm}) \times$ width $(\mathrm{mm}) \times$ correction factor (0.75) [9].

Table 1. Details of parameters

\begin{tabular}{|c|c|c|c|}
\hline $\begin{array}{c}\text { Vegetative } \\
\text { Parameters }\end{array}$ & $\begin{array}{c}\text { Reproductive } \\
\text { Parameters }\end{array}$ & $\begin{array}{c}\text { Qualitative } \\
\text { Parameter }\end{array}$ & Quantitative Parameters \\
\hline Leaf area & Number of fruits & Taste & $\begin{array}{c}\text { Chlorophyll contents (vegetative \& } \\
\text { reproductive stage) }\end{array}$ \\
\hline & Fruit weight & Color & Total soluble solids \\
\hline
\end{tabular}


Number of fruits were picked and then counted. Three berries from each treatment were randomly selected and average weight of berry was recorded on "electronic balance SF-400" and expressed in grams. Taste was checked by eating strawberry fruit from each treatment. The scale for taste was (Sweet, sour, Bitter). In each treatment 5 fruits were collected on random basis and taste score chart was developed to measure the fruit taste of each treatment. The fruit color was observed on visual basis. The scale for color was (Pink, light pink, red, dark red). The color of five fruits per treatment was collected for color scoring and their average was taken. Five plants per treatment were tagged and counted for chlorophyll content by using "Chlorophyll meter CL-101". Chlorophyll content of strawberry were measured from the leaves at vegetative and reproductive stages. Total soluble solids of the five fresh fruits were recorded by using "Digital Refractometer LH-T80" at room temperature and expressed in ${ }^{0} \mathrm{Brix}$. The juice of each fruit was extracted and a drop of juice was dropped on the lens of refractometer then clean with distilled water after each observation (Table 2).

Table 2. Comparison of means of fertilizer and media on strawberry plant for leaf area, chlorophyll content at vegetative $\&$ reproductive stage

\begin{tabular}{|c|rc|c|cc|}
\hline Treatment & \multicolumn{2}{|c|}{ Leaf Area $(\mathbf{m m})$} & $\begin{array}{c}\text { Chlorophyll content at } \\
\text { Vegetative stage }\end{array}$ & \multicolumn{2}{|c|}{$\begin{array}{c}\text { Chlorophyll content at } \\
\text { Reproductive stage }\end{array}$} \\
\hline $\mathrm{M}_{1} \mathrm{~T}_{0}$ & 165.19 & $\mathrm{E}$ & $15.36 \mathrm{BC}$ & $12.25 \mathrm{EF}$ \\
\hline $\mathrm{M}_{1} \mathrm{~T}_{1}$ & 240.00 & $\mathrm{E}$ & $14.46 \mathrm{BCD}$ & $11.13 \mathrm{~F}$ \\
\hline $\mathrm{M}_{1} \mathrm{~T}_{2}$ & 341.47 & $\mathrm{D}$ & $14.86 \mathrm{BCD}$ & 15.40 & $\mathrm{CDE}$ \\
\hline $\mathrm{M}_{1} \mathrm{~T}_{3}$ & 342.10 & $\mathrm{D}$ & $12.36 \mathrm{DEF}$ & 15.28 & $\mathrm{CDE}$ \\
\hline $\mathrm{M}_{2} \mathrm{~T}_{0}$ & 345.33 & $\mathrm{D}$ & $19.23 \mathrm{~A}$ & 17.79 & $\mathrm{BCD}$ \\
\hline $\mathrm{M}_{2} \mathrm{~T}_{1}$ & 413.25 & $\mathrm{CD}$ & $11.43 \mathrm{EF}$ & $23.68 \mathrm{~A}$ \\
\hline $\mathrm{M}_{2} \mathrm{~T}_{2}$ & 473.87 & $\mathrm{BC}$ & $12.93 \mathrm{CDEF}$ & 13.51 & $\mathrm{EF}$ \\
\hline $\mathrm{M}_{2} \mathrm{~T}_{3}$ & 516.18 & $\mathrm{~B}$ & $13.86 \mathrm{BCDE}$ & 13.06 & $\mathrm{EF}$ \\
\hline $\mathrm{M}_{3} \mathrm{~T}_{0}$ & 485.99 & $\mathrm{BC}$ & $10.70 \mathrm{~F}$ & 18.77 & $\mathrm{BC}$ \\
\hline $\mathrm{M}_{3} \mathrm{~T}_{1}$ & 522.70 & $\mathrm{~B}$ & $15.73 \quad \mathrm{~B}$ & $19.69 \mathrm{~B}$ \\
\hline $\mathrm{M}_{3} \mathrm{~T}_{2}$ & 501.14 & $\mathrm{~B}$ & $19.60 \mathrm{~A}$ & 12.57 & $\mathrm{EF}$ \\
\hline $\mathrm{M}_{3} \mathrm{~T}_{3}$ & 625.86 & $\mathrm{~A}$ & $16.30 \mathrm{~B}$ & $14.22 \mathrm{DEF}$ \\
\hline
\end{tabular}

Means followed by a different letter indicates significant differences between two treatments at $\mathrm{P}<.05$

\section{Statistical analysis}

The data was analyzed by using STATISTIX 8.1 and means were compared by using Least Significant Difference (LSD) test at 5\% probability level [10].

\section{Results and discussion}

Statistical analysis of data including leaf area showed significant effect of media and fertilizer (Table 3). Maximum leaf area $(625.86 \mathrm{~mm})$ was observed in peat moss by 8ppm foliar application of NPK. While, minimum $(165.19 \mathrm{~mm})$ were observed in soil with 4ppm foliar application of NPK (Table
2). The combination of peat moss media with foliar application of macro nutrients increase the stem and leaf area. The foliar application of macronutrients make direct availability of nitrogen by to leaves and peat moss media also provide all kind of nutrients to the plant roots, making them capable to grow maximum as compared to the soil media.

Maximum leaf area was observed in peat moss with foliar application of NPK. Ogendo et al. [11] reported that peat moss have the sufficient amount of potassium which increased leaf growth and increased the sugar 
accumulation which promotes the leaf area. Minimum leaf area observed in soil may be due to inadequate amount of macro and micro nutrients in soil conditions Abu-Zahra and Tahboub [12] reported the same result.

Statistical analysis of data including chlorophyll content showed significant effect of media and fertilizer (Table 3). Maximum chlorophyll content (19.6) at vegetative stage was observed in peat moss by 8 ppm foliar application of NPK. While, minimum (10.7) were observed in soil with $8 \mathrm{ppm}$ foliar application of NPK (Table 4). Because phosphorus was unavailable for the plants in soil as compared to peat moss, as much the phosphorus will be present in the plant leaves, more chlorophyll content will be produced.

Table 3. Analysis of variance showing the mean squares of parameters as influenced by macronutrient (T), media (M) and their interaction (TxM)

\begin{tabular}{|c|c|c|c|}
\hline Parameters & $\begin{array}{c}\text { Media }(\mathbf{M}) \\
(\mathbf{D F}=\mathbf{2})\end{array}$ & $\begin{array}{c}\text { Macronutrients } \\
\text { concentration }(\mathbf{T})(\mathbf{D F}=3)\end{array}$ & M x T (DF=6) \\
\hline Leaf Area & $42933^{* *}$ & $210170^{* *}$ & $3893^{* *}$ \\
\hline $\begin{array}{c}\text { Chlorophyll content at } \\
\text { vegetative stage }\end{array}$ & $6.93 \mathrm{~ns}$ & $6.44 \mathrm{~ns}$ & $36.69^{* *}$ \\
\hline $\begin{array}{c}\text { Chlorophyll content at } \\
\text { reproductive stage }\end{array}$ & $36.56 \mathrm{~ns}$ & $41.08 \mathrm{~ns}$ & $43.088^{* *}$ \\
\hline Number of Fruits & $1.1 * *$ & $25.03 \mathrm{~ns}$ & $2.72 \mathrm{~ns}$ \\
\hline Fruit weight & $90.17 * *$ & $316^{* *}$ & $10.812 \mathrm{~ns}$ \\
\hline Total soluble solids & $5.85 \mathrm{~ns}$ & $0.33^{* *}$ & $0.66 \mathrm{~ns}$ \\
\hline
\end{tabular}

Ns, non-significant; *, P $<0.05 ; * *, \mathrm{P}<0.01$

Table 4. Comparison of means of fertilizer and media on strawberry plant for number of fruits, fruit weight, total soluble solids, color and taste of fruit

\begin{tabular}{|c|c|c|c|c|c|}
\hline Treatment & No. of fruits & $\begin{array}{c}\text { Fruit weight } \\
\text { (g) }\end{array}$ & $\begin{array}{c}\text { Total Soluble } \\
\text { Solids } \\
\end{array}$ & Color Scale & Taste Scale \\
\hline $\mathrm{M}_{1} \mathrm{~T}_{0}$ & $2.77 \quad \mathrm{D}$ & $5.95 \quad \mathrm{~F}$ & $7.33 \quad \mathrm{AB}$ & Light pink & Sweet \\
\hline $\mathrm{M}_{1} \mathrm{~T}_{1}$ & 3.33 BCD & 7.09 & $5.10 \quad \mathrm{~B}$ & Pink & Sour \\
\hline $\mathrm{M}_{1} \mathrm{~T}_{2}$ & $3.22 \quad \mathrm{CD}$ & 10.53 & $7.99 \quad \mathrm{~A}$ & Pink & Sour \\
\hline $\mathrm{M}_{1} \mathrm{~T}_{3}$ & $5.67 \quad \mathrm{AB}$ & 10.83 & $6.74 \quad \mathrm{ABC}$ & Pink & Sour \\
\hline $\mathrm{M}_{2} \mathrm{~T}_{0}$ & $5.20 \quad \mathrm{ABC}$ & 6.66 & $7.00 \mathrm{AB}$ & Red & Sweet \\
\hline $\mathrm{M}_{2} \mathrm{~T}_{1}$ & $5.33 \mathrm{ABC}$ & 8.733 & $5.89 \mathrm{DE}$ & Light red & Bitter \\
\hline $\mathrm{M}_{2} \mathrm{~T}_{2}$ & $6.33 \quad \mathrm{~A}$ & $10.04 \quad \mathrm{DEF}$ & $6.61 \mathrm{~A}$ & Light pink & Sour \\
\hline $\mathrm{M}_{2} \mathrm{~T}_{3}$ & $5.33 \mathrm{ABC}$ & 12.65 & $6.93 \mathrm{E}$ & Light pink & Sour \\
\hline $\mathrm{M}_{3} \mathrm{~T}_{0}$ & $7.21 \quad \mathrm{~A}$ & 12.02 & $7.61 \quad \mathrm{AB}$ & Dark red & Bitter \\
\hline $\mathrm{M}_{3} \mathrm{~T}_{1}$ & 6.33 & 15.97 & 5.83 DEF & Dark red & Sweet \\
\hline $\mathrm{M}_{3} \mathrm{~T}_{2}$ & 6.66 & 23.52 & $7.33 \quad \mathrm{~A}$ & Red & Sweet \\
\hline $\mathrm{M}_{3} \mathrm{~T}_{3}$ & 6.22 & 20.15 & $6.93 \mathrm{AB}$ & Dark red & Sweet \\
\hline
\end{tabular}

Means followed by a different letter indicates significant differences between two treatments at $\mathrm{P}<.05$

Statistical analysis of data regarding chlorophyll content at reproductive stage showed significant effect of media and fertilizer (Table 3). Maximum chlorophyll 
(23.69) content at reproductive stage was observed in peat moss by $6 \mathrm{ppm}$ foliar application of NPK. While, minimum (11.13) were observed in soil with 4ppm foliar application of NPK (Table 4). Peat moss provides all the nutrients in available form for the plant roots, if we provide foliar support to plant then it could be more vigorous as we can see there is maximum chlorophyll in peat moss media as compared to soil media and by foliar application we can have direct availability of NPK at leaves.

NPK is provided to the plant for maximum growth at reproductive and vegetative stages, chlorophyll content directly relates with phosphorus, as in soil it is not mostly present in free state, because it makes bonding with different micro and macro nutrients.

Statistical analysis of data regarding number of fruits showed significant effect of media and fertilizer (Table 2). Maximum number of fruits (7.21) were observed in soil by $8 \mathrm{ppm}$ foliar application of NPK. While, minimum (2.77) were observed in soil with 4ppm foliar application of NPK (Table 4).

In 2011 scientist Herencia et al [13] reported that organic media contains phosphorus and nitrogen which increase flower bud initiation and growth. Our results are also similar with their findings. Foliar application of NPK in a sufficient amount fulfills the unique formulation of natural growth promoters, which has proven to substantially increase flowering and fruiting. Phosphorous is important for energy storage and development of fruit. Both the media (peat moss) and foliar application of NPK increased the no of fruits. In our soil available phosphorus was 7 , with $8 \mathrm{pH}$ and $128 \mathrm{ds} / \mathrm{m}$ Ec which promoted the runners growth in the form of maximum fruits. Deficiency of nitrogen could be indicated by less number of flower and fruits at time of flowering through which flower size decreased and female flower part aborted [14].
Statistical analysis of data regarding fruit weight showed significant effect of media and fertilizer (Table 3). Maximum fruit weight (23.52) was observed in peat moss by 8 ppm foliar application of NPK. While, minimum (5.95) were observed in soil with 4ppm foliar application of NPK.

Peat moss contains favorable amounts of micro and macro nutrients which increased the fruit weight by the formation of carbohydrates. Ripening process in which, fruits play a role for nitrogen and potassium and peat moss have sufficient amount of important nutrients. Peat moss contains micro and macro nutrients in Free State, which could be easily uptake by roots. Potassium relates with ripening of fruits, foliar application of NPK produces the fruit more healthy because of direct availability of potassium.

Statistical analysis of data regarding Total soluble salts showed significant effect of media and fertilizer (Table 3). Maximum TSS (7.99 ${ }^{0}$ Brix) was observed in peat moss by 4ppm foliar application of NPK. While, minimum $\left(5.10{ }^{0}\right.$ Brix $)$ were observed in soil with 4ppm foliar application of NPK (Table 4).

Our findings agree with the work Mahadeen [15] and Tuzel et al. [16] on strawberry and tomatoes respectively, which reported that there was no effect of media on TSS contents of these Crops. Maximum TSS was found in peat moss media because it provided the micro and macro nutrients to the plant in free state, so it produces more number of seeds in reproductive stage, the minimum amount of TSS was found in soil+ peat moss because when we mixed soil with peat moss, nature of both media were changed, soil provided some of nutrients to the plants while it also interrupted the peat moss mechanism, which results in less TSS in fruits.

Maximum sweet taste was observed in peat moss with 8ppm foliar application of NPK while, minimum were observed in soil with 4ppm application of NPK. Maximum dark 
red color was observed in peat moss with 8ppm foliar application of NPK while, minimum were observed in soil with $4 \mathrm{ppm}$ application of NPK. In strawberry flavor is developed by ripening process. Highest sugar content and flavor is obtained at full ripened stage. However, fruit which is harvested at a stage when not fully ripened would be firm enough to be shipped.

\section{Conclusions}

Strawberry plant showed better results towards peat moss with6 and 8 ppm foliar application of NPK. Maximum leaf area $(625.86 \mathrm{~mm})$ was observed in peat moss by $8 \mathrm{ppm}$ foliar application of NPK. While, minimum $(165.19 \mathrm{~mm})$ were observed in soil with 4ppm foliar application of NPK. Maximum chlorophyll content (19.6) at vegetative stage was observed in peat moss by $8 \mathrm{ppm}$ foliar application of NPK. While, minimum (10.7) were observed in soil with 8ppm foliar application of NPK. Maximum chlorophyll (23.69) content at reproductive stage was observed in peat moss by $6 \mathrm{ppm}$ foliar application of NPK. While, minimum (11.13) were observed in soil with 4ppm foliar application of NPK. Maximum number of fruits (7.21) was observed in soil by $8 \mathrm{ppm}$ foliar application of NPK. While, minimum (2.78) were observed in soil with 4ppm foliar application of NPK. It is therefore, concluded that among all the three medias strawberry plants responded better on peat moss based growing medium with 6 and 8ppm foliar application of NPK as compared to control.

\section{Authors' contributions}

Conceived and designed the experiments:

U Shahzad \& TA Yasir, Performed the experiments: S Rasheed \& M Shahjahan Analyzed the data: A Wasaya \& AW Baloch Contributed materials/ analysis/ tools: Z Hassan, Wrote the paper: U Shahzad \& S Rasheed.

\section{References}

1. Hancock JF (1999). Strawberries crop production science in horticulture. CABI, Publishing, Oxon, Uk. pp. 109-112.

2. Sharma RR (2004). Growing strawberry. Int Book Distributing Co Indian 1: 01-02.

3. Hakkinen SH \& Torronen AR (2000) .Content of flavonols and selected phenolic acids in strawberries and Vaccinium species influence of cultivar, cultivation site and technique. Food Res Int 33: 517-524.

4. Milosevic T (1997). Special topics in fruit growing. Faculty of agronomy and community for fruits and vegetables. Cacek-Belgrade. pp. 353-384.

5. Khushk AM \& Memon A (2005). Strawberry cultivation. The Dawn. pp. 15.

6. Du GD, Guo XW, Wu J \& Cai M (2007). Effect of different medias aeration on growth and photosynthetic characteristic of strawberry. College of Horticulture Shenyang Agricultural University, Liaoning, Shenyang.

7. Martinez F, Castillo S, Borrero C, Perez S, Palencia P \& Aviles M (2013). Effect of different soilless growing systems on the biological properties of growth media in strawberry. Scient Hort 150: 59-64.

8. Swietlik D \& Faust M (1984). Foliar nutrition of fruit crops. Hort Reviews 6: 287-356.

9. Gower ST, Kucharik, CJ \& Norman JM (1999). Direct and Indirect Estimation of Leaf Area Index, Fapar, and Net Primary Production of Terrestrial Ecosystems. Remote Sensing of Environment 70: 2951.

10. Steel RGD, Torrie JH \& Dickey DA. Principles and procedures of statistics; a biometrical approach. 3. Boston: McGraw-Hill; 1997.

11. Ogendo RO, Isutsa DK \& Sigunga DO (2008). Interaction of farmyard manure and plant population density effects on soil characteristics and productivity of 
mulched strawberry in a tropical climate. Afr J Hort Sci 1: 100-115.

12. Abu-Zahra TR \& Tahboub AA (2009). Strawberry (Fragaria ananassa Duch.) fruit quality grown under different organic matter sources in a plastic house at Humrat Al-Sahen. Acta Hort 807: 353-358.

13. Herencia JF, Garcia-Galavisa PA, Doradoa JAR \& Maqueda C (2011). Comparison of nutritional quality of the crops grown in an organic and conventional fertilized soil. Sci Hort 129: 882-888.

14. Tagliavini M, Baldi E, Nestby $R$, Ryanal-Lacroix C, Lieten P, Salo T,
Pivot D, Lucchi PL, Baruzzi G \& Faedi W (2004). Uptake and partitioning of major nutrients by strawberry plants. Acta Hort 2: 649.

15. Mahadeen, AY (2009). Influence of organic and chemical fertilization on fruit yield and quality of plastic-house grown strawberry. J Agric Sci 5: 167177.

16. Tuzel Y, Anac D \& Tuzel IH (2003). Effects of different organic fertilizers and irrigation levels on yield and quality of organically grown greenhouse tomatoes. Ege. Univ. of Agric., Depts. of Hort., Soil Sci., Plant Protect, Bornova, Izmir, Turkey. 